Volume 2, Nomor 2, Maret 2022, hlm 94-103

BEMAS: JURNAL BERMASYARAKAT

p ISSN 27455866 | e ISSN 27457958

\title{
Mentoring Women's Farmer Groups in Utilizing Yard Land as an Effort for Food Security in the Pandemic Period
}

\author{
Ratna Susanti $^{1 *}$, Suci Purwandari ${ }^{2}$ \\ 1* Study Program of Mass Communication, Politeknik Indonusa Surakarta, Indonesia \\ ${ }^{2}$ Study Program of Automotive Technology, Politeknik Indonusa Surakarta, Indonesia \\ $1^{*, 2}$ Jl. K.H Samanhudi No.31, Bumi, Kec. Laweyan, Kota Surakarta, Jawa Tengah 57149
}

\begin{tabular}{l} 
INFORMASI ARTIKEL \\
\hline Article History: \\
Submission: $10 / 11 / 2021$ \\
Revised:28/11/2021 \\
Accepted:09/12/2021 \\
* Korespondensi: \\
Ratna Susanti \\
ratnasusanti19@poltekindonusa.ac.id
\end{tabular}

INFORMASI ARTIKEL

Submission: 10/11/2021

Revised:28/11/2021

* Korespondensi

ratnasusanti19@poltekindonusa.ac.id

\begin{abstract}
ABSTRAK
The objectives of this community service are: 1. assisting women farmer groups in the use of yard land, 2. educating women farmer groups in efforts to food security during the pandemic. This community service was carried out for 3 months, namely April, May, and June 2021 through the following methods: 1) lectures by the implementation team for the Women Farmer Group in Baran village, Cawas, Klaten who attended a total of 52 people regarding food security education in during the pandemic, 2) distribution of assistance for a number of vegetable seeds to be planted in a predetermined yard, 3) assistance in planting and using vegetables as a source of family nutrition. The result of this community service is that the women in Baran Village, Cawas, Klaten who are members of the Women Farmers Group have an independent business in the form of vegetable plants as a source of nutrition that can be used as a share of crop yields: from, by, for the Woman Farmer Group members.
\end{abstract}

Keywords: women farmer groups; food security; yards, pandemic

\section{Pendampingan Kelompok Wanita Tani Desa Baran, Cawas, Klaten dalam Pemanfaatan Lahan Pekarangan sebagai Upaya Ketahanan Pangan di Masa Pandemi}

ABSTRACT
Tujuan pengabdian masyarakat ini adalah: 1. mendampingi kelompok
wanita tani (KWT) Desa Baran Cawas, Klaten dalam pemanfaatan lahan
pekarangan, 2. mengedukasi kelompok wanita tani dalam upaya
ketahanan pangan di masa pandemi. Pengabdian masyarakat ini dilakukan
selama 3 bulan, yaitu bulan April, Mei, dan Juni 2021 melalui metode: 1)
ceramah oleh tim pelaksana pengabdian kepada kelompok wanita tani
(KWT) desa Baran, Cawas, Klaten yang hadir berjumlah 52 orang
mengenai edukasi ketahanan pangan di masa pandemi, 2) penyaluran
bantuan pupuk organik, alat penyiram tanaman, jaring paranet, dan
sejumlah bibit sayuran untuk ditanam di lahan pekarangan yang telah
ditentukan, 3) pendampingan dalam penanaman dan pemanfaatan sayuran


sebagai sumber gizi keluarga. Hasil dari pengabdian masyarakat ini adalah para ibu di Desa Baran, Cawas, Klaten yang tergabung dalam kelompok wanita tani (KWT) memiliki usaha mandiri berupa tanaman sayuran sebagai sumber gizi yang dapat dimanfaatkan sebagai bagi hasil panen: dari, oleh, untuk anggota KWT.

Kata kunci: kelompok wanita tani; ketahanan pangan; lahan pekarangan, pandemi

\section{PENDAHULUAN}

Kabupaten Klaten merupakan salah satu dari 29 kabupaten di Jawa Tengah. Kabupaten Klaten terdiri dari 26 kecamatan yakni, Prambanan, Gantiwarno, Wedi, Bayat, Cawas, Trucuk, Kebonarum, Jogonalan, Manisrenggo, Karangnongko, Ceper, Pedan, Karangdowo, Juwiring, Wonosari, Delanggu, Polanharjo, Karanganom, Tulung, Jatinom, Kemalang, Ngawen, Kalikotes, Klaten Utara, Klaten Tengah, dan Klaten Selatan. Secara geografis Kabupaten Klaten terletak diantara $110^{\circ} 30^{\prime}-110^{\circ} 45^{\prime}$ Bujur Timur dan $7^{\circ} 30^{\prime}-7^{\circ} 45^{\prime}$ Lintang Selatan. Batas-batas wilayah Kabupaten Klaten adalah sebagai berikut. Sebelah utara berbatasan dengan Kabupaten Boyolali, sebelah timur berbatasan dengan Kabupaten Sukoharjo, sebelah selatan berbatasan dengan Kabupaten Gunungkidul (Daerah Istimewa Yogyakarta), dan sebelah barat berbatasan dengan Kabupaten Sleman (Daerah Istimewa Yogyakarta).

Topografi Kabupaten Klaten terletak di antara Gunung Merapi dan Pegunungan Seribu dengan ketinggian antara 75 hingga 160 Meter di atas permukaan laut yang terbagi menjadi wilayah Lereng Gunung Merapi di bagian utara areal miring, wilayah datar dan berbukit di bagian selatan. Jika ditinjau dari ketinggiannya, Kabupaten Klaten terdiri dari dataran dan pegunungan yang berada pada ketinggian bervariasi, yaitu 9,72 persen terletak di ketinggian 0-100 meter dari permukaan air laut. 77,52 persen terletak di ketinggian 100-500 Meter dari permukaan air laut dan 12,76 persen terletak di ketinggian 500-1.000 meter dari permukaan air laut. Keadaan iklim Kabupaten Klaten termasuk iklim tropis dengan musim hujan dan kemarau silih berganti sepanjang tahun, temperatur udara rata-rata 28 30 derajat Celcius dengan kecepatan angin rata-rata sekitar 153 milimeter setiap bulannya dengan curah hujan tertinggi pada bulan Januari $(350 \mathrm{~mm})$ dan curah hujan terendah pada bulan Juli $(8 \mathrm{~mm})$. (www.pemkabklaten.go.id)

Sebagian besar lahan di Desa Baran berupa sawah, tegalan, dan sebagian yang lainnya dimanfaatkan untuk pemukiman penduduk, dan pekarangan. Lahan pertanian tanaman pangan dan sayuran di Desa Baran sejak beberapa tahun terakhir mengalami penyusutan. Untuk memenuhi kebutuhan pangan, masyarakat Desa Baran membeli di warung atau pasar sehingga menambah pengeluaran keluarga. Dengan kondisi ekonomi yang kurang mendukung akibat pandemi Covid-19 seperti sekarang ini, menyebabkan beban keluarga semakin berat.

Masyarakat Desa Baran sebagian besar berprofesi sebagai petani, namun dalam mengelola halaman dan pekarangan untuk budidaya tanaman pangan masih terbatas. Hal ini karena keterbatasan pengetahuan dan keterampilannya [1]. Oleh karena itu, dilakukan kegiatan pengabdian pada masyarakat dengan tujuan menjadikan pekarangan rumah di Desa Baran menjadi lahan pertanian produktif, serta meningkatkan pengetahuan, wawasan dan keterampilan masyarakat Desa Baran dalam mengelola lahan pekarangan untuk budidaya tanaman pangan sebagai sumber gizi keluarga di masa pandemi covid-19 [2]. Pada saat tim pelaksana melakukan observasi ke Desa Baran didapati banyak lahan pekarangan warga yang belum dimanfaatkan secara optimal [3]. 
Pendampingan Kelompok Wanita Tani Desa Baran, Cawas, Klaten dalam Pemanfaatan Lahan

Pekarangan sebagai Upaya Ketahanan Pangan di Masa Pandemi

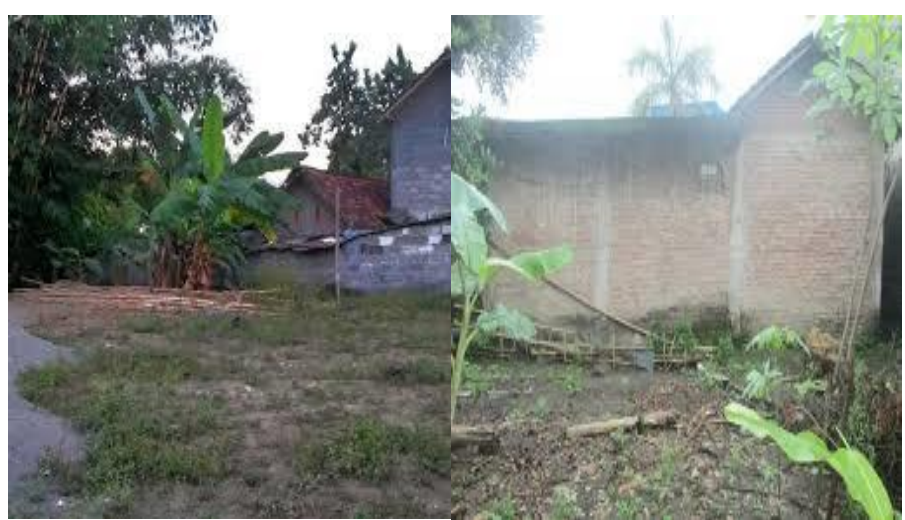

Gambar 1. Kondisi lahan pekarangan warga yang tidak dimanfaatkan dengan baik.

Salah satu tujuan pengabdian masyarakat bagi KWT (Kelompok Wanita Tani) Desa Baran ini adalah mendorong warga, khususnya ibu-ibu anggota KWT untuk memanfaatkan ruang terbatas seperti pekarangan atau halaman rumah untuk berkebun atau menanam tanaman, termasuk sayuran, guna memenuhi kebutuhan pangan rumah tangga selama pandemi Covid-19. Oleh karenanya, tim pengabdi berdasarkan observasi awal menyarankan untuk menanam sayuran yang bisa dikonsumsi dan dijual hasilnya.

Pangan merupakan kebutuhan pokok bagi kehidupan manusia, sehingga keberadaannya akan selalu dibutuhkan [4][5]. Ketahanan pangan merupakan salah satu kunci dalam membangun keluarga yang tangguh, sehingga perlu diupayakan alternatif untuk memenuhi kebutuhan bahan pangan tersebut [6].

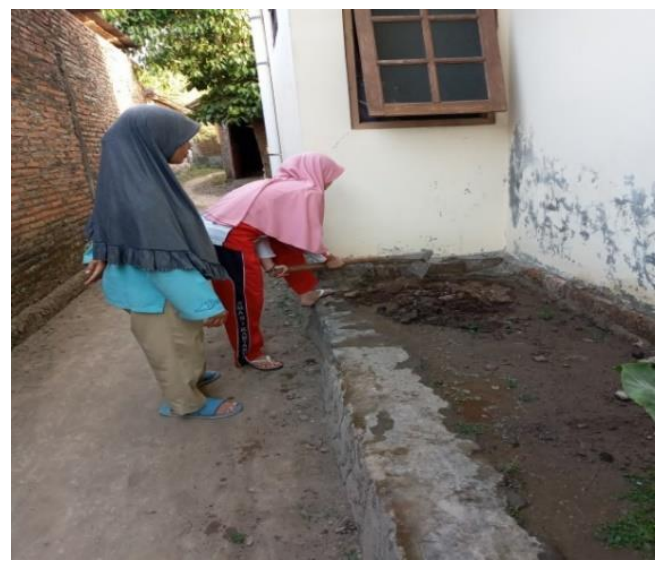

Gambar 2. Pemanfaatan lahan pekarangan.

Salah satu lahan yang potensial untuk dikelola menjadi lahan pertanian untuk menghasilkan bahan pangan adalah pekarangan [7][8]. Pekarangan berpotensi untuk dikembangkan sebagai lumbung pangan sebab letaknya yang dekat dengan pemukiman sehingga pengelolaannya dapat dilakukan lebih intensif sehingga harapannya hasilnya lebih baik sehingga dapat meningkatkan pendapatan keluarga [9][10][11]. Selain untuk tujuan produksi, halaman dan pekarangan yang dikelola dengan baik akan menjadi lebih asri dan nyaman [12].

\section{METODE PELAKSANAAN}

Pelaksana pengabdian masyarakat menggunakan langkah-langkah berikut ini dalam melaksanakan pengabdian kepada masyarakat bagi KWT Desa Baran, Cawas, Klaten.

a. Pengumpulan Data 
Pengumpulan data dilakukan dengan observasi, partisipasi aktif, diskusi, dan wawancara, serta dokumentasi kegiatan. Kegiatan ini dilakukan untuk memperoleh data primer dari lapangan dengan ditunjang data sekunder. Kegiatan dilakukan selama satu minggu mendatangi lokasi.

b. Pelaksanaan Pengabdian kepada Masyarakat

Langkah-langkah untuk menggiatkan para anggota KWT untuk dapat memanfaatkan lahan pekarangan agar ditanami jenis sayur-sayuran sebagai sumber gizi keluarga melalui ceramah dan diskusi.

c. Pendampingan

Kegiatan pengabdian pada masyarakat di Desa Baran, Cawas, Klaten dilakukan dengan metode partisipatif, melalui beberapa tahapan mulai dari koordinasi dan sosialisasi kepada masyarakat, implementasi di lapangan, sampai monitoring dan evaluasi. Kegiatan ini melibatkan tim pengabdian dari Politeknik Indonusa Surakarta, Kepala Desa, Ketua RT, Ketua RW, dan ibu-ibu yang tergabung dalam Kelompok Wanita Tani Desa Baran. Koordinasi dilakukan sebelum program pengabdian pada masyarakat dimulai. Selanjutnya dilakukan sosialisasi kegiatan kepada ibu-ibu KWT Desa Baran dan diikuti kegiatan penyuluhan, pelatihan, praktik pengelolaan pekarangan, pendampingan, serta monitoring dan evaluasi. Penyuluhan dilakukan dengan mengumpulkan ibu-ibu anggota KWT untuk menjelaskan tentang pemanfaatan dan pengelolaan pekarangan dan halaman rumah. Pelatihan dilakukan dengan cara demonstrasi dan praktik pengelolaan pekarangan dan halaman rumah dilakukan oleh ibu-ibu KWT. Pendampingan, monitoring, dan evaluasi dilakukan dengan mengunjungi masyarakat dalam melakukan praktik pemanfaatan dan pengelolaan pekarangan dan halaman rumah.

\section{HASIL DAN PEMBAHASAN}

Sebelum tim pengabdian pada masyarakat melakukan kegiatan di lapangan, pada tanggal 4 April 2021 terlebih dahulu dilakukan kegiatan studi pendahuluan (preliminary research dan observasi). Kegiatan ini dimaksudkan untuk mendapatkan informasi yang komprehensif tentang potret riil dan kondisi objektif masyarakat yang dijadikan sasaran program (subyek kegiatan). Selain itu juga untuk menggali permasalahan yang dihadapi masyarakat, tanah pekarangan yang bisa dikembangkan, sumber daya yang ada, serta fasilitas sarana dan prasarana pendukung yang bisa dimanfaatkan. Observasi juga bertujuan untuk mengetahui sejauh mana visibilitas program Kelompok Wanita Tani melalui pemanfaatan tanah pekarangan untuk mendukung perwujudan program pemerintah yaitu ketahanan pangan keluarga. Proses pelaksanaan studi pendahuluan dan observasi dilakukan dengan cara mengadakan komunikasi dan koordinasi dengan pihak-pihak stakeholders terkait yang terlibat, yaitu Ibu Kepala Desa, Ibu RT, Ibu RW, dan pengurus KWT Desa Baran.

Program pengabdian kepada masyarakat di Desa Baran, Cawas, Klaten dirasakan sangat bermanfaat terutama setelah WHO menetapkan Covid-19 sebagai pandemi (Kemenkes RI, 2020). Dampak akibat Covid-19 dirasakan seluruh penduduk dunia dan menyentuh seluruh aspek kehidupan, termasuk di bidang pertanian. Pembatasan sosial menyebabkan aktivitas petani dalam mengelola lahan pertanian menjadi terbatas, sehingga pengelolaan halaman dan pekarangan rumah menjadi sebuah alternatif untuk memenuhi kebutuhan pangan masyarakat (Setiawan \& Wijayanti, 2020). Pengabdian pada masyarakat di Desa Baran dimulai pada awal bulan April 2021, diawali dengan koordinasi internal oleh Tim pelaksana dosen dan mahasiswa, dilanjutkan dengan koordinasi eksternal dengan Ketua RW, Ketua RT, dan Ketua KWT Desa Baran untuk menentukan tahapan dan jadwal kegiatan.

Kegiatan sosialisasi disampaikan oleh Tim Pelaksana dengan dihadiri oleh ibu-ibu anggota KWT Desa Baran, sebagaimana pada ditunjukkan pada Gambar 1 dan Gambar 2. Peserta yang hadir sejumlah 52 orang ibu yang tergabung dalam Kelompok Wanita Tani Desa Baran, Cawas, Klaten. Pada saat awal penyuluhan, didapatkan data bahwa anggota KWT yang memiliki pemahaman mengenai pemanfaatan lahan pekarangan dengan baik sehingga dapat diolah dan dimanfaatkan untuk 
Pendampingan Kelompok Wanita Tani Desa Baran, Cawas, Klaten dalam Pemanfaatan Lahan

Pekarangan sebagai Upaya Ketahanan Pangan di Masa Pandemi

menanam tanaman sayuran maupun tanaman toga lainnya. Sebanyak 36 orang yang paham tentang pemanfaatan lahan pekarangan, 11 orang kurang paham cara memanfaatkan lahan pekarangan dengan baik, dan 5 orang tidak paham cara memanfaatkan lahan pekarangan dengan baik sehingga dapat dimanfaatkan untuk membantu pemenuhan kebutuhan sehari-hari bagi keluarganya di masa pandemic Covid-19 ini [13].

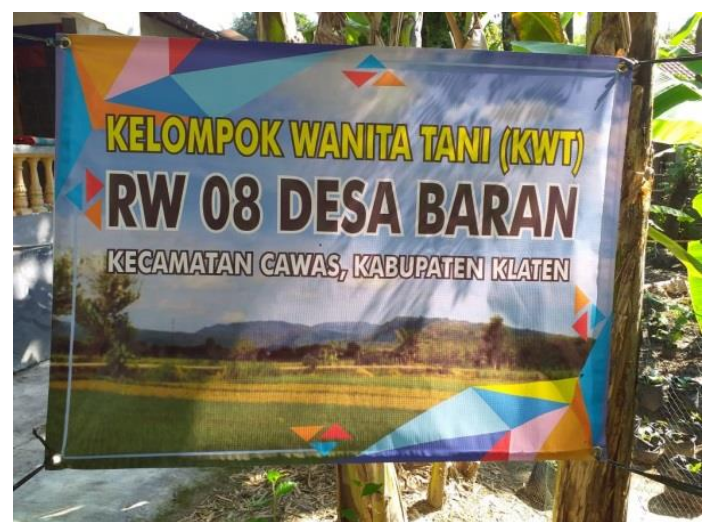

Gambar 1. Banner KWT Desa Baran

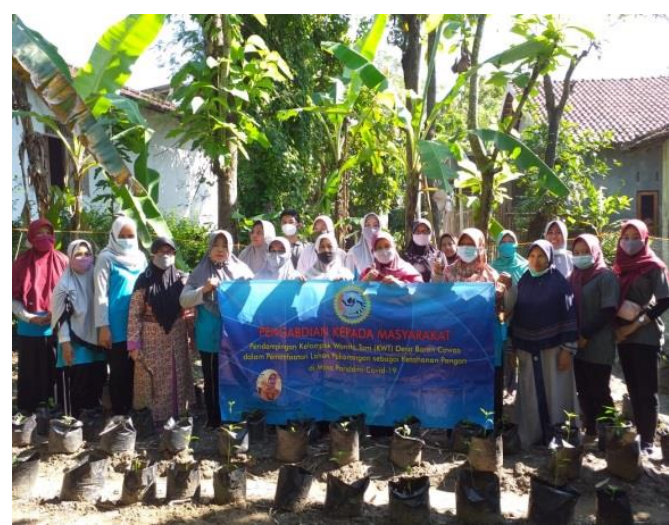

Gambar 2. Ibu-ibu KWT Desa Baran

Dari hasil observasi kemudian disusun langkah-langkah pelaksanaan program melalui beberapa tahapan yaitu penyuluhan, pelatihan, dan praktik lapangan serta monitoring. Anggota KWT Desa Baran juga merupakan anggota PKK Desa Baran yang mayoritas sebagai ibu rumah tangga dan pekerja/wanita karir. Rata-rata usianya 30-50 tahun, namun ada beberapa sebagian kecil yang berusia di atas 50 tahun. Tingkat pendidikan rata-rata yang lulus SMA, namun sebagian kecil ada yang lulusan perguruan tinggi (diploma dan sarjana).

Peningkatan keterampilan tentang pemanfaatan dan pengelolaan tanah pekarangan serta teknik budidaya tanaman yang benar diharapkan berdampak pada peningkatan kesejahteraan keluarga serta dapat mewujudkan dan melaksanakan program KWT. Setelah dilakukan observasi kegiatan dilanjutkan dengan penyuluhan tentang pemanfaatan pekarangan dan pelaksanaan program KWT. Penyuluhan dilakukan pada hari Minggu tanggal 4 April 2021. Materi yang diberikan dalam penyuluhan adalah menanam harapan dan memupuk semangat di hati ibu-ibu KWT Desa Baran, Cawas, Klaten untuk berdaya guna di tengah pandemi Covid-19 ini. Selain itu memberi pengertian dan pemanfaatan pekarangan untuk mewujudkan ketahanan pangan keluarga. Selain penyuluhan juga dilakukan diskusi dengan tujuan untuk mengetahui tingkat pemahaman ibu-ibu anggota KWT dan memberikan kesempatan bagi anggota kelompok untuk bertanya seluas-luasnya tentang cara pemanfaatan tanah pekarangan dengan tanaman yang produktif dan bernilai gizi untuk keluarga.

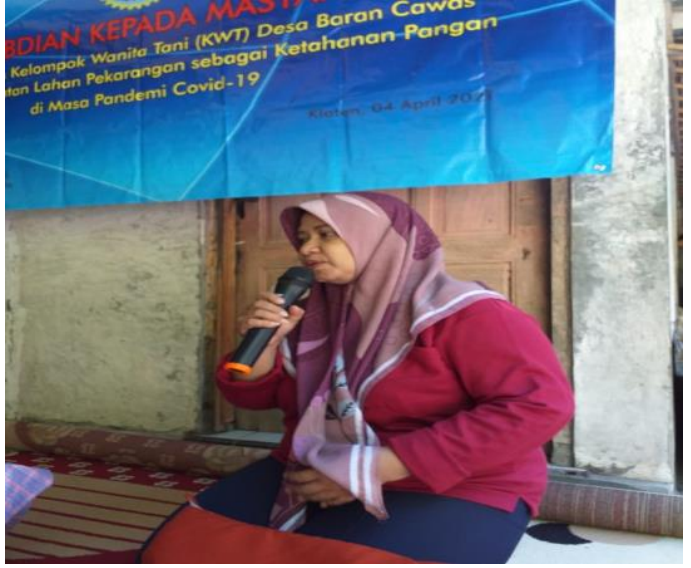

Gambar 3. Penyuluhan pemanfaatan lahan

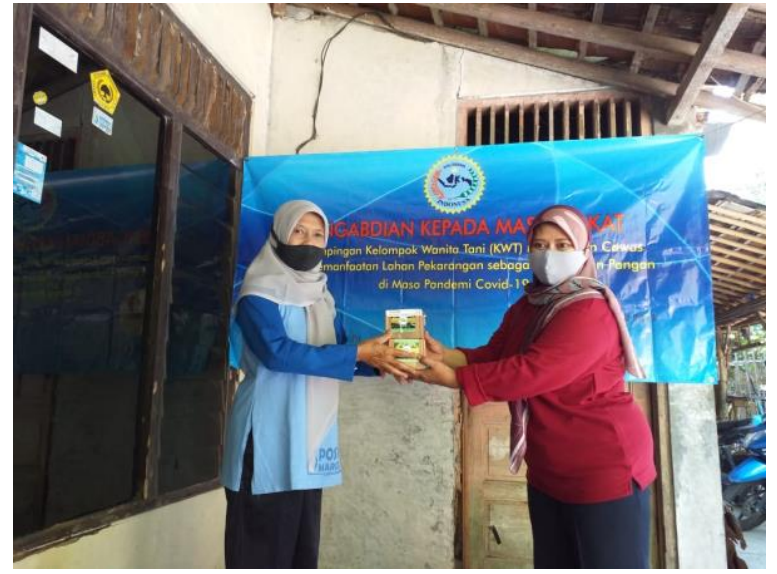

Gambar 4. Pemberian bibit tanaman sayuran 


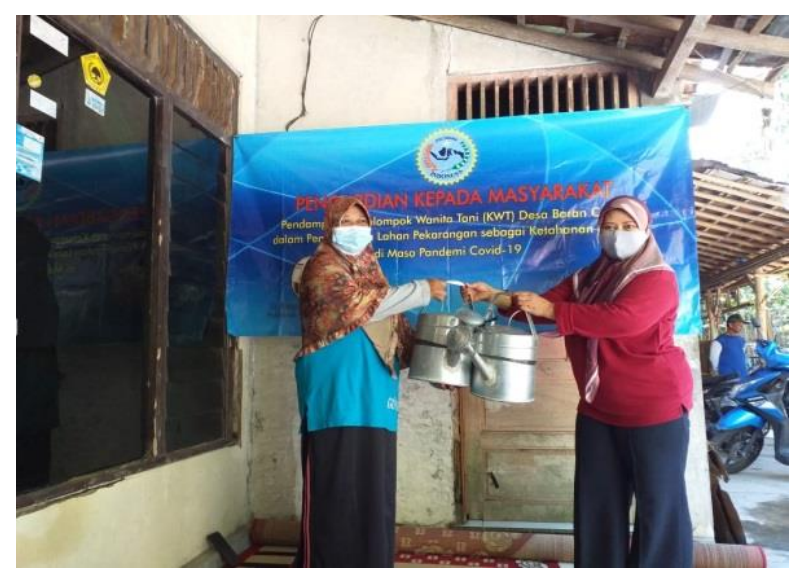

Gambar 5. Pemberian alat siram tanaman

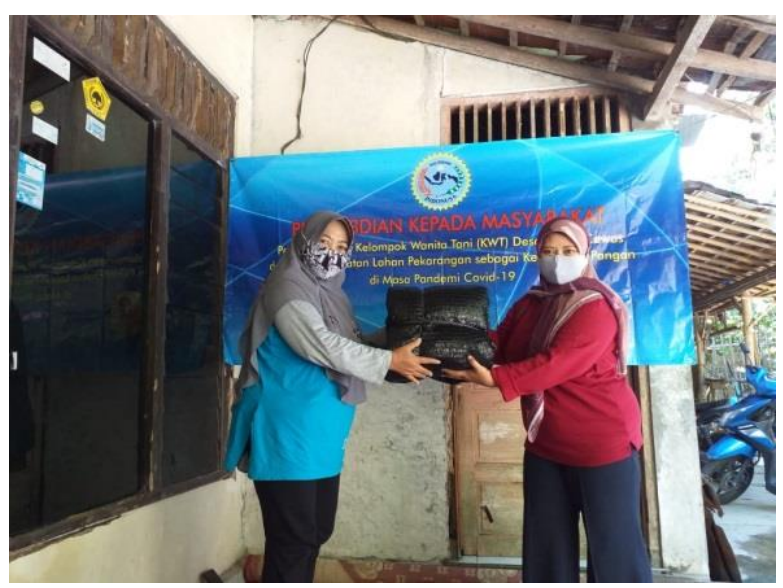

Gambar 6. Pemberian paranet untuk melindungi tanaman

Setelah kegiatan penyuluhan dan kegiatan selanjutnya adalah pemberian bantuan berupa sejumlah bibit tanaman sayuran, alat penyiram tanaman, paranet untuk melindungi tanaman kepada KWT yang diterimakan kepada pengurus, selanjutnya dilakukan praktik langsung tentang pemanfaatan tanah pekarangan untuk budidaya tanaman sayur.

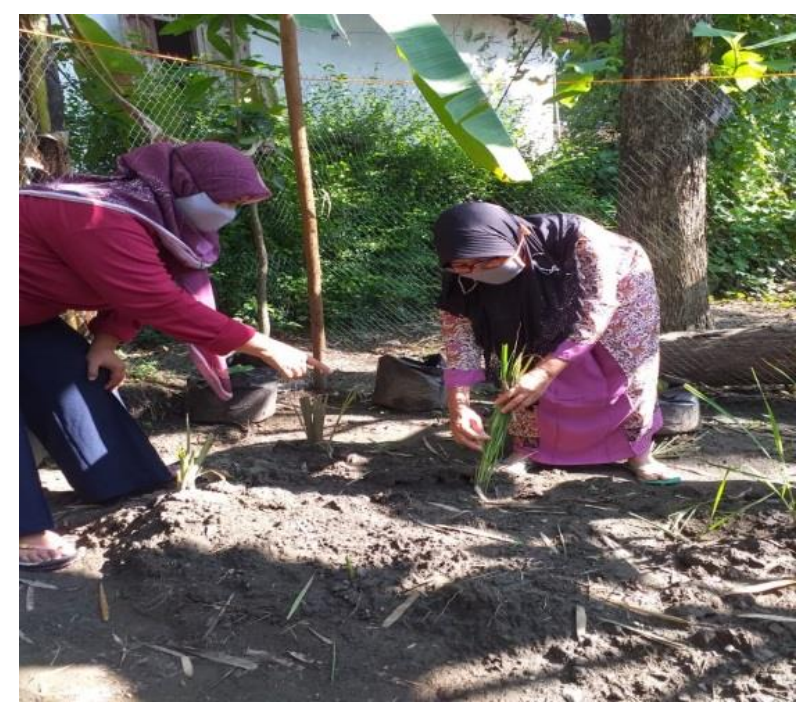

Gambar 7. Menanam sereh

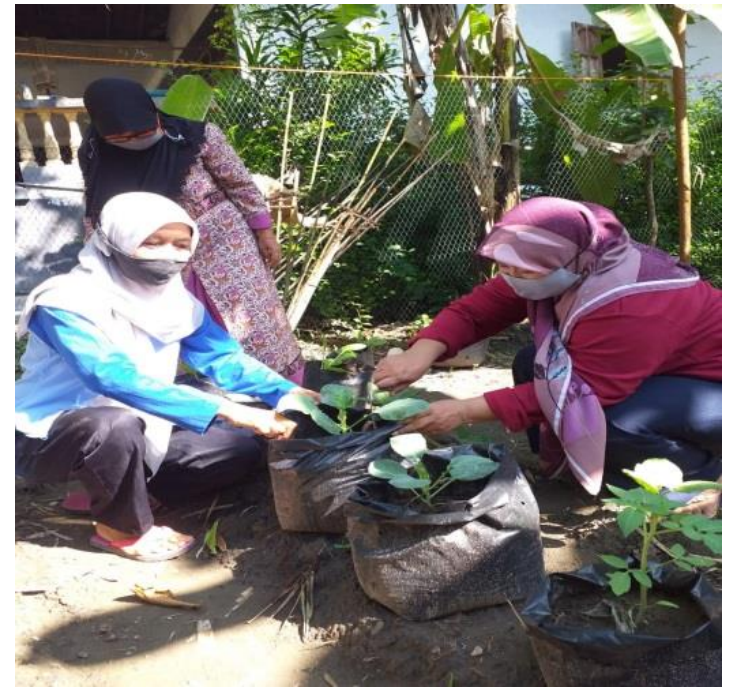

Gambar 8. Menanam sayuran terong dan cabai

Kegiatan penanaman tersebut dilakukan di lahan pekarangan milik salah satu pengurus KWT Desa Baran, yaitu Ibu Titik Sutardi. Pada saat dilakukan praktik, anggota kelompok kelihatan sangat antusias untuk mengetahui bagaimana cara memanfaatkan tanah pekarangan secara optimal dengan budidaya tanaman yang baik dan benar. Selanjutnya, tim pengabdi dari Politeknik Indonusa Surakarta memberikan bibit tanaman sayuran sejumlah 25 jenis untuk dibagi kepada anggota KWT lainnya agar dilakukan penyemaian dan penanaman di lahan pekarangan masing-masing. 
Pendampingan Kelompok Wanita Tani Desa Baran, Cawas, Klaten dalam Pemanfaatan Lahan

Pekarangan sebagai Upaya Ketahanan Pangan di Masa Pandemi

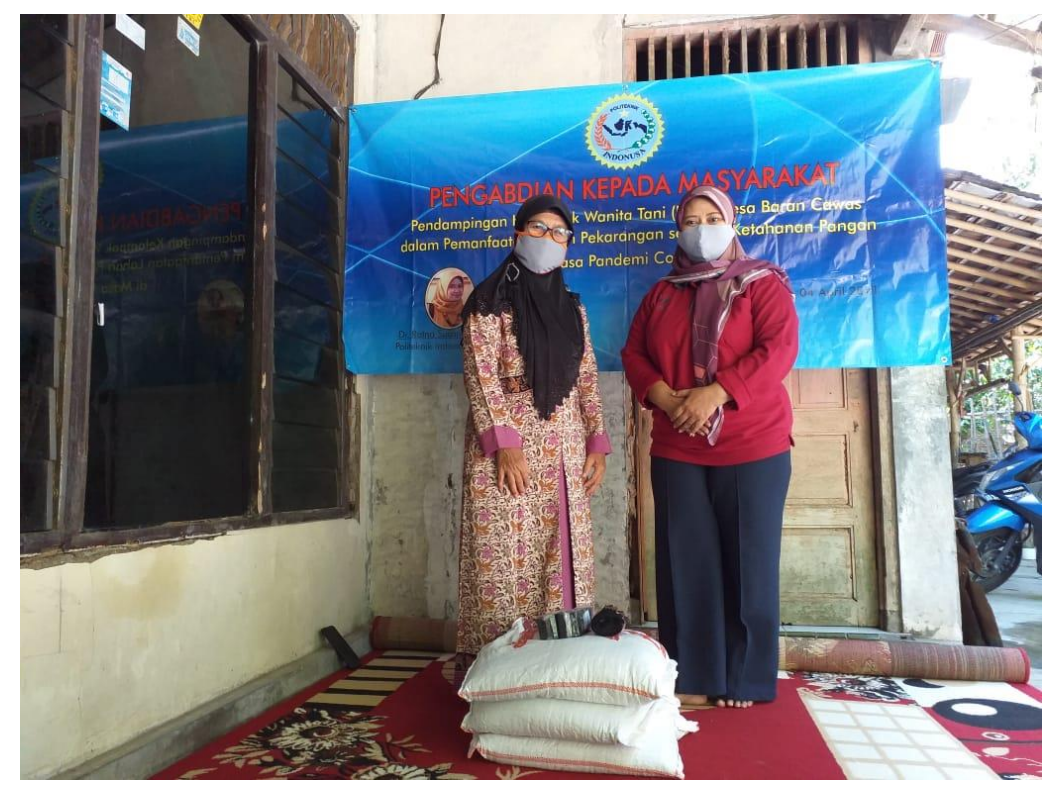

Gambar 8. Pemberian pupuk organik dan polibag

Kegiatan selanjutnya adalah memonitoring hasil kegiatan yang dilakukan pada Sabtu, 1 Mei 2021 oleh tim pengabdi dan anggota kelompok yaitu dengan memantau keberhasilan anggota kelompok dalam memanfaatkan tanah pekarangan untuk budidaya berbagai jenis tanaman.

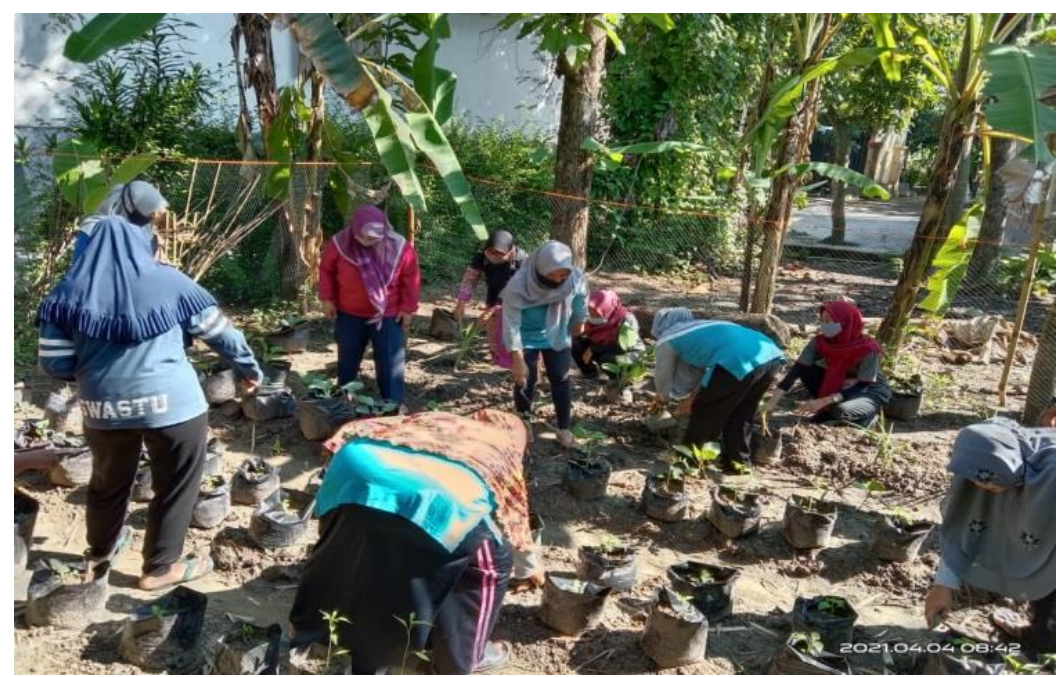

Gambar 9. Monitoring penanaman bibit sayuran di lahan pekarangan milik anggota KWT

Hasil pelaksanaan kegiatan pengabdian ini menunjukkan indikasi sebagai berikut.

a. Peningkatan pengetahuan dan keterampilan dalam memanfaatkan tanah pekarangan dan teknik budidaya tanaman sayuran di polybag. Peningkatan ditunjukkan dengan adanya pemahaman dari para ibu anggota Kelompok Wanita Tani Desa Baran terhadap pemanfaatan lahan pekarangan dengan baik sehingga dapat diolah dan ditanami berbagai tanaman sayuran, baik melalui media polybag maupun ditanam di tanah pekarangan.Sebelum tim pelaksana memberikan penyuluhan dan pendampingan, dari

b. Penyuluhan dan pelatihan tentang pemanfaatan tanah pekarangan untuk budidaya tanaman khususnya untuk memenuhi kebutuhan pangan dan gizi keluarga telah dilaksanakan. Dengan penyuluhan dan pelatihan tersebut secara keseluruhan dapat meningkatkan pengetahuan dan keterampilan tentang pemanfaatan lahan pekarangan serta teknik budidaya tanaman dengan baik. 
c. Dengan pengetahuan dan keterampilan yang dimiliki ibu-ibu anggota KWT dapat mengatur dan mengelola serta memanfaatkan lahan pekarangan dengan baik. Selain itu kebutuhan akan sayur dan bumbu dapur dengan standar kualitas tinggi, bergizi, dan aman dapat dicukupi oleh dirinya sendiri tanpa harus membeli dari luar sehingga dapat meningkatkan kesejahteraan dan perekonomian keluarga.

d. Peningkatan kebersihan dan kenyamanan lingkungan ibu-ibu KWT Desa Baran bahwa lahan pekarangan yang tidak dimanfaatkan serta dikelola dengan baik membuat lingkungan sekitar tempat tinggal menjadi terlihat kotor dan tidak nyaman serta tidak enak dilihat. Dengan kegiatan ini membantu meningkatkan pemahaman dan pengetahuan tentang pentingnya lingkungan serta halaman yang asri, teratur, indah, dan nyaman sehingga dapat meningkatkan kesehatan keluarga untuk menjaga konservasi lingkungan dan mengurangi global warming.

e. Terbentuknya kader ketahanan pangan keluarga ibu-ibu anggota KWT yang telah sadar akan pentingnya pemanfaatan lahan pekarangan dengan tanaman yang produktif nantinya akan terbentuk kader KWT dalam hal ketahanan pangan keluarga.

Program kegiatan kepada masyarakat ini berpotensi untuk terus berkembang dan berkelanjutan seiring dengan situasi dan kondisi pandemic Covid-19 yang belum berakhir hingga sekarang. Dalam situasi pandemi seperti ini, masyarakat khususnya ibu-ibu KWT diharapkan dapat meningkatkan keterampilan dalam mengolah ketahanan pangan dan ekonomi keluarga. Adapun hasil penyuluhan dan pendampingan dari tim pelaksana, maka didapatkan hasil peningkatan terhadap pemahaman ibu-ibu anggota KWT Desa Baran, Cawas, Klaten terhadap upaya pemanfaatan lahan pekarangan yang semua mangkrak tidak maksimal pemanfaatannya, berubah menjadi paham dalam memanfaatkan lahan pekarangan agar menghasilkan produk yang bernilai gizi tinggi berupa tanaman sayuran atau tanaman toga lainnya sehingga dapat dimanfaatkan untuk peningkatan gizi keluarga di masa pandemic Covid19 ini. Setelah dilakukan wawancara singkat terhadap para ibu anggota KWT Desa Baran, Cawas, Klaten melalui Ketua KWT, yaitu Ibu Titik Sutardi, maka didapatkan angka peningkatan pemahaman ibu-ibu KWT dalam memanfaatkan lahan pekarangan sebagai berikut.

Tabel 1. Pemahaman Ibu-Ibu KWT dalam Pemanfaatan Lahan Pekarangan

\begin{tabular}{llll}
\hline \multicolumn{2}{c}{ Sebelum Penyuluhan dan Pendampingan } & \multicolumn{2}{c}{ Setelah Penyuluhan dan Pendampingan } \\
\hline \multicolumn{1}{c}{ Kategori } & \multicolumn{1}{c}{ Jumlah } & \multicolumn{1}{c}{ Kategori } & \multicolumn{1}{c}{ Jumlah } \\
\hline Paham Sekali & 26 Orang & Paham sekali & 36 Orang \\
Paham & 11 Orang & Paham & 14 Orang \\
Kurang Paham & 10 Orang & Kurang paham & 2 Orang \\
Tidak Paham & 5 Orang & Tidak paham & 0 Orang \\
\hline Total & 52 Orang & Total & 52 Orang \\
\hline
\end{tabular}

Berdasarkan tabel 1, diperoleh data terjadi peningkatan pemahaman dari ibu-ibu anggota KWT Desa Baran, Cawas, Klaten dalam hal pemanfaatan lahan pekarangan sehingga dapat menghasilkan produk tanaman sayuran yang bernilai gizi sebagai bahan pangan keluarga di masa pandemic Covid19. Melalui gerakan pemanfaatan lahan pekarangan ibu-ibu KWT Desa Baran, Cawas, Klaten dapat berkreasi di lahan pekarangannya masing-masing dengan berbagai macam varian tanaman yang produktif dan berguna. Metode penanamannya juga bisa divariasi melalui tabulampot (tanaman buah dan sayur dalam pot) atau melalui media hidroponik [14][15].

\section{SIMPULAN}

Simpulan dari kegiatan pengabdian masyarakat ini adalah sebagai berikut. a) Program pengabdian pada masyarakat yang dilaksanakan oleh tim pengabdi yang terdiri atas dosen dan mahasiswa 
Pendampingan Kelompok Wanita Tani Desa Baran, Cawas, Klaten dalam Pemanfaatan Lahan

Pekarangan sebagai Upaya Ketahanan Pangan di Masa Pandemi

Politeknik Indonusa Surakarta ini telah berjalan baik. Beberapa kegiatan yang dilakukan adalah koordinasi, sosialisasi, penyuluhan, pelatihan dan praktik pengelolaan halaman dan pekarangan, pendampingan, serta monitoring dan evaluasi. b) Partisipasi masyarakat Desa Baran dalam hal ini KWT Desa Baran dalam kegiatan cukup tinggi, dan memberikan hasil masyarakat mampu mengelola pekarangan dan mampu mewujudkan halaman asri, teratur, indah dan nyaman, serta produktif. c) Program pengabdian pada masyarakat telah memberikan kemanfaatan yang luas dengan mampu menyediakan berbagai bahan pangan dari hasil panen di pekarangan dalam masa pandemi Covid-19.

\section{UCAPAN TERIMA KASIH}

Tim pengabdi mengucapkan terima kasih disampaikan kepada Direktur dan Ketua UPPM Politeknik Indonusa Surakarta yang telah mengizinkan dan menyetujui kegiatan pengabdian pada masyarakat ini, mahasiswa Politeknik Indonusa Surakarta yang telah membantu pelaksanaan di lapangan, dan ibu-ibu anggota KWT Desa Baran, Cawas, Klaten yang berperan aktif dalam berbagai kegiatan.

\section{DAFTAR PUSTAKA}

[1] S. N. Wijayanti and A. N. Setiawan, "PENGELOLAAN PEKARANGAN UNTUK KETAHANAN PANGAN DI MASA PANDEMI COVID-19," Pros. Semin. Nas. Progr. Pengabdi. Masy., 2021, doi: 10.18196/ppm.34.299.

[2] Kusumiyati, W. Sutari, and Farida, "Pemanfaatan Lahan Pekarangan Rumah Untuk Budidaya Tanaman Cabai Rawit Secara Hidroponik," J. Pengabdi. Kpd. Masy., vol. 4, no. 4, 2019.

[3] A. Yusuf, "Optimalisasi Lahan Pekarangan Untuk Mendukung Ketahanan Pangan Dan Ekonomi Keluarga," J. Pengabdi. Kpd. Masy., vol. 2, no. 2, 2018.

[4] S. N. Wijayanti and A. N. Setiawan, "Pengelolaan Pekarangan Untuk Ketahanan Pangan Di Masa Pandemi Covid-19," in Prosiding Seminar Nasional Program Pengabdian Masyarakat, 2021, pp. 812-817, doi: 10.18196/ppm.34.299.

[5] Y. Probowati, "Pemberdayaan PKK dengan Pemanfaatan Lahan Pekarangan untuk Mendukung Program Ketahanan Pangan Keluarga," in Prosiding Konferensi Nasional Pengabdian Kepada Masyarakat dan Corporate Social Responsibility (PKM-CSR), 2020, vol. 3, pp. 463-469, doi: 10.37695/pkmcsr.v3i0.812.

[6] M. Fauzi, R. Kastaman, and T. Pujianto, "Pemetaan Ketahanan Pangan Pada Badan Koordinasi,” Ind. Pertan., vol. 01, 2019.

[7] R. Kurniawan, G. A. Nurhaliza, H. K. Maharani, and E. Sufanti, "Inovasi keluarga berkebun untuk meningkatkan ketananan pangan keluarga," SeTIA Mengabdi - J. Pengabdi. Kpd. Masy., vol. 2, no. 1, pp. 31-36, 2021.

[8] A. N. Setiawan and S. N. Wijayanti, "Pengelolaan Pekarangan Melalui Hatinya PKK untuk Ketahanan Pangan dalam Menghadapi Pandemi Covid-19," PRIMA J. Community Empower. Serv., vol. 4, no. 2, p. 95, 2020, doi: 10.20961/prima.v4i2.43327.

[9] G. Priyandoko, R. M. A. Hutagalung, and ..., "Berkebun di Pekarangan Rumah Sebagai Upaya Ketahanan Pangan di Masa Pandemi Warga Kampung Herbal Sukolelo, Pandaan, Kabupaten Pasuruan," Pros. ..., vol. 1, no. Vol. 1 (2020): SEMADIF, pp. 1-6, 2020.

[10] L. Rosidah, I. Rosmilawati, R. Kusumawardani, and D. Darmawan, "Ketahanan Pangan Keluarga Pasca Covid-19 Melalui Pemanfaatan Pekarangan Sebagai Lumbung Pangan Keluarga," Murhum J. Pendidik. Anak Usia Dini, 2021, doi: 10.37985/murhum.v2i1.12.

[11] A. Hamzah, D. Sri, and U. Lestari, "RUMAH PANGAN LESTARI ORGANIK SEBAGAI SOLUSI PENINGKATAN PENDAPATAN KELUARGA,” 2016.

[12] A. Zannati, "Ketahanan Pangan di Masa Pandemi COVID-19: Langkah Indonesia dengan Food Estate," BioTrends, vol. 11, no. 2, pp. 29-34, 2020. 
[13] G. Krisna, "Sosialisasi Pemanfaatan Toga Untuk Ibu-Ibu Pkk Desa Ringinputih Kabupaten Ponorogo," J. KARINOV, vol. 3, no. Vol 3, No 2 (2020): Mei, 2020.

[14] M. Faizah, M. Nasirudin, and B. Prakasa, "Pemanfaatan Pekarangan dengan Metode Tanam Hidroponik dari Botol Bekas," Jumat Pertan. J. Pengabdi. Masy., vol. 1, no. 1, 2020.

[15] S. Wibowo, "PEMANFAATAN LAHAN PEKARANGAN DENGAN HIDROPONIK SEDERHANA OLEH KWT SIDA MAKMUR PUCANG BANJARNEGARA," J. Penelit. dan Pengabdi. Kpd. Masy. UNSIQ, vol. 8, no. 3, 2021, doi: 10.32699/ppkm.v8i3.1487. 